\title{
Impact of Training on Nurses Performance and Productivity at Neonatal Intensive Care Unit (NICU)
}

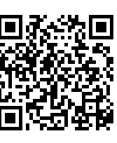

\author{
Laila Rahimi, Zohra Javed, Kashif Abbas, Brig Anwer Ali Khan, Naseem Kauser and Rufina Somroo* \\ ${ }^{1}$ Laila Rahimi RN, Human Resource Management
}

${ }^{2}$ Zohra Javed RN, Deputy Manager Nursing Education Services

${ }^{3}$ Syed Kashif Abbas, Department of pediatrics and neonatology

${ }^{4}$ Anwer Ali Khan, Controller Nursing Brigadier

${ }^{5}$ Naseem Kauser, Health Management Head of Nursing

${ }^{6}$ Rufina Soomro, Department of Surgery, Pakistan

Submission: August 06, 2018; Published: August 15, 2018

*Corresponding author: Rufina Soomro, Liaquat National Hospital \& Medical College Karachi, Pakistan, Email: rufina.soomro@lnh.edu.pk

\begin{abstract}
Introduction: Neonatal Nursing is Sub-Specialty of Nursing that works with Newborns born with variety of problems. It generally encompasses care for those neonates who experiences problems shortly after the first initial hours of birth till 28 days of life. So, it is essentially important for caregivers to undergo training that not only enhance knowledge but bring change in behavior by holding accountability to care neonates and to meet general to specific needs.
\end{abstract}

Objective and Purpose: Objective of the study was to assess the impact of training on Nurses Knowledge and Skills working at Neonatal Intensive Care Unit.

Methodology: An Experimental Study was made and Basic Neonatology Course in collaboration with Department of Pediatrics, Nursing Education Services and Research Development and Skill Center of Liaquat National Hospital. The Program was initiated to train nurses and doctors dealing with neonates. Course evaluation was based on Pre and Post Test on ICU infection module, Mid-Quiz and Final Quiz based on different Sections. For skills development clinical Simulators were used at Skills Development Centre (RSDC) and rotations were done Neonatal Intensive care (NICU), Pleads OPD and Well Baby Centre were selected. Paired T-Test and ANOVAs was applied.

Results: Total 25 participants were enrolled. We found significant differences in mean scores $26.82 \pm 6.16$ and $31.9 \pm 10.45$ of mid quiz and final quiz respectively $(\mathrm{p}=0.005)$.

Conclusions: Study showed the impact of training on all participation and validated the significance of continuous nursing education and contributed to make nurses valuable and safe by enduring high quality care to neonates and helped nurses to have sound proficiency at NICU.

\section{Introduction}

The Care of Newborn and premature babies have undergone major development in recent years. Premature holds high rate of morbidity than full term babies. Nurses working with this specialty need to be clinically sound to provide quality care to sick neonates with general to specific medicine and surgical needs. Newborns are born with variety of problems and first 28 days of life are essential for them to survive. An article by Haydeh Heidari [1] was one of the sources of inspiration with Title "Stress management among parents of Neonates hospitalized in NICU". Where authors had talked on the bonding of neonates to their parents as there is interruption and delays in paternal and neonate bonding and attachments. From same it was articulated that research on maternal - infant bonding has revealed that contact with infants is fundamentally important for the development of maternal self-confidence, security, sentimental emotional stability and preparation for learning about infant's growth and development. Maintaining calm among parents of sick neonate is challenging for health professionals working in NICU. This research had highlighted the most significant aspect of care where parents collectively shared that supportive staffs had a positive effect on their ability to maintain calm. "We feel calm when we see how nurses are working hardly and it gives us hope that their hard work and God's will are going to help our baby get better". Although the impact of developmental care on premature infants has been investigated at length, often the issue of professional development and training related to this type of care has not been examined Milette [2].

The daily Rounds at NICU and need expressed by nurses we planned a training program especially for Neonatal Nurses. Many nurses expressed when they undergo professional qualification 
diploma or degree program, they are trained in general nursing aspects and when transition phase is encountered, and Units are assigned to enter in world of many sub-specialty which College of Nursing presently don't have in their curriculum Sheri Price [3] wrote in one of the Article Administrative Sciences: The Importance of Continuous Professional Development to Career Satisfaction.... Nurses throughout their Career Span" that data collection showed Nurses wrote "We have a great general education that gives great head Start, but Now I'm Looking for Education. I'm looking for more specialized training and I'm Finding it's really hard to find". Based on the fact Neonate Post Basic Course Training was to see its impact on performance and productivity of Nurses and Midwifes working in NICU.

\section{Purpose}

The aim of the study was to educate nurses to gain the necessary knowledge and skills to be able to provide specialized care to neonates. The impact of training was seen in cardiorespiratory support, care of neonate going under surgical procedure and disease processes and work as team in promotion of recovery for sick neonate from serious illness and meet patient satisfaction standards.

\section{Study Design, Material and Method}

An Experimental Study was made, and Basic Neonatology Course conducted in collaboration with Department of Peads and Nursing Education Services along with Research Development and Skill Center of Liaquat National Hospital. It was combining effort taken to Train Nurses and doctors dealing with Neonates. Pre and Post Test on ICU infection module was taken followed with Mid-Quiz based on different Sections (Section A: MCQs, Section B: Case Study, fill in the blanks, true and false, Section C: was of small essay questions and Section D: Bonus question). Final Quiz was subjective Based with Short essay Questions, while for Clinical Simulators at RSDC were used, NICU, Peads OPD and Well Baby. Paired T-Test and ANOVAs was applied.

Training was done over period of 9 days, total of 45 hours. Total Theory Hours were of 32.5 and clinical hours 12.5 hours. There were 25 Participants. Clinical Location was as Research and Skills Center, Well Baby Nursery, NICU and Pediatric OPD at Liaquat National Hospital. For the first time it happened that Team of Pediatric Faculties and Surgeons from Medicine and Surgery, Residents from Medicine and Surgery, Nursing Managers departmental and Nursing Education Services, Research and Skills development Center Team, Infection Control and Head Nurses joined hands and came forward to train nurses. Altogether there were (28 Trainers). This was the set example of team approach which in actual reflected on purpose of the training. The nurses and independent raters found scenario-based simulation training more effective than traditional communication course. Introduction of simulation-based training to in-service nursing education could enhance nurses' communication performance in clinical practice HSU LL [4].
Participants were from different Hospitals Liaquat National Hospital and Medical College (LNHMC), Hamdard University and Hospital (HUH) and Memon Medical Institute and Hospital (MMIH) - As Shown in Figure 1. Unit Based participation was seen where neonates are been cared; Labour Room, Neonatal high dependency Unit, Neonate intensive care unit, Pediatric (Combine Specialty of Medicine and surgical), Peads Intensive Care Unit and High Dependency Unit. Inclusion Criteria was Inclusion Criteria: Nurses and Doctors working in NICU and those dealing mainly neonates and Exclusion Criteria: Nurses and Doctors not working in NICU and neither deal patient's category (neonates) - Figure 2.

Learning is one of the necessary conditions to transfer what was taught to a daily working practice and it is processed as soon as the person appropriates a certain knowledge as articulate by Mira VL [5] Interactive session through Presentations, were made by team of trainers on different topics which includes neonatal medicine, neonatal surgery, neonatal infectious disease and other general to specific are of newborns. Evaluation was done by conducting Mid Quiz to assess knowledge of disease process along with Nursing Care and Responsibilities. Mid Quiz consists of MCQs, Case Study, Fill in the blanks and true and false. This was significant markup that benefitted us not only to understand Knowledge level of the nurses but also their ability to comprehend with variety of questions style. Participants who had put a word with exact Responses in Case Scenario rated full as per section marks. Interestingly, responses in Quiz were checked by team and it was also found that People were comfortable more on responding Short essay questions. So, one of the learning limitations was noted and planned accordingly in promoting and enhancing concept building and critical thinking. Group Presentation was made to develop good group dynamics. Reflective Writings were part of every day. Cases were discussed, and thought-provoking question were given, and queries related were discussed and cleared. Final Quiz was conducted based on Short essay questions. Recommendations and conclusions were done with participants and trainers on one platform.

\section{Statistical Analysis}

Statistical Package for the Social Sciences Software (SPSS, version 21) was used for analysis. Quantitative variables such as scores of midterm, final term, pretest and posttest were presented in terms of Mean \pm SD. Qualitative variables as gender, institutes, hospital units and designation were presented in terms of frequency and percentages. Student t-test and ANOVA was applied for finding mean differences between quantitative variables. P-value $\leq 0.05$ was considered as significant.

\section{Results}

In our study, 25 participants were enrolled. 11(44\%) were males and $14(56 \%)$ were females. They all were from different institutes in which $19(76 \%)$ from LNH, 4(16\%) from $\mathrm{HUH}$, $2(8 \%)$ from $\mathrm{MMH}$. Out of all, $4(16 \%)$ from labor room, $1(4 \%)$ from neonatal HDU, 4(16\%) from NICU, 6(24\%) from paeds, $1(4 \%)$ from paeds medicine, $3(12 \%)$ from paeds surgery, $4(16 \%)$ 
from PICU, well baby nursery $2(8 \%)$. According to designation, only $1(4 \%)$ was senior resident, $2(8 \%)$ were resident, $15(60 \%)$ were RN, 4(16\%) were RM and 3(12\%) were RN/RM. We found significant differences in mean scores $26.82 \pm 6.16$ and $31.9 \pm 10.45$ of midterm and final term respectively $(\mathrm{p}=0.005)$. The mean score of pretests based on MCQ's criteria was 10.76 \pm 2.11 and mean score of posttests based on subjective question was $12.10 \pm 1.8$, which shows the significant differences in mean scores of pre and posttest criteria $(p=0.002)$. It also indicates that the mean score of posttest increases as compared to pretest (Figures $1 \& 2$ ).

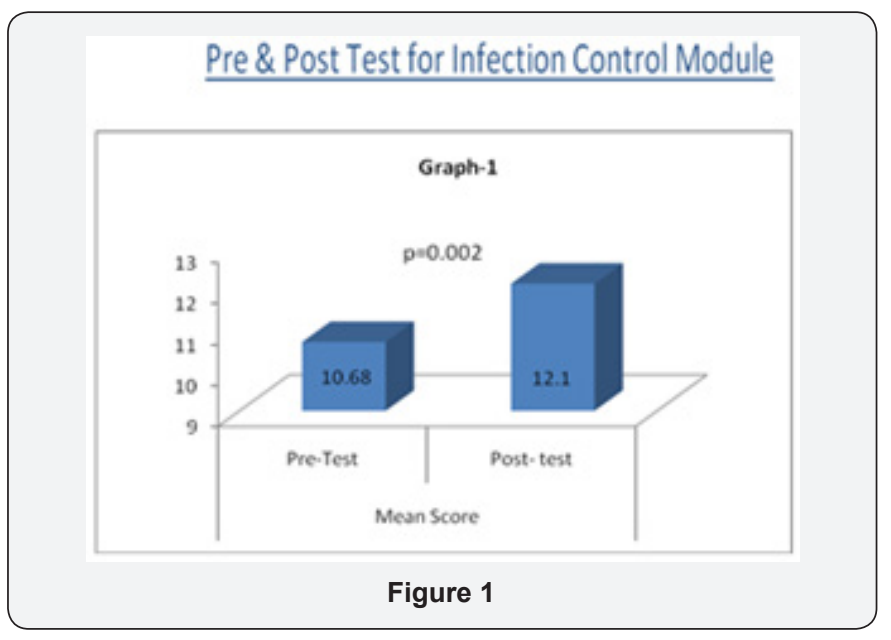

\section{Mid Quiz and Final Quiz (Disease \& Care Processes)}

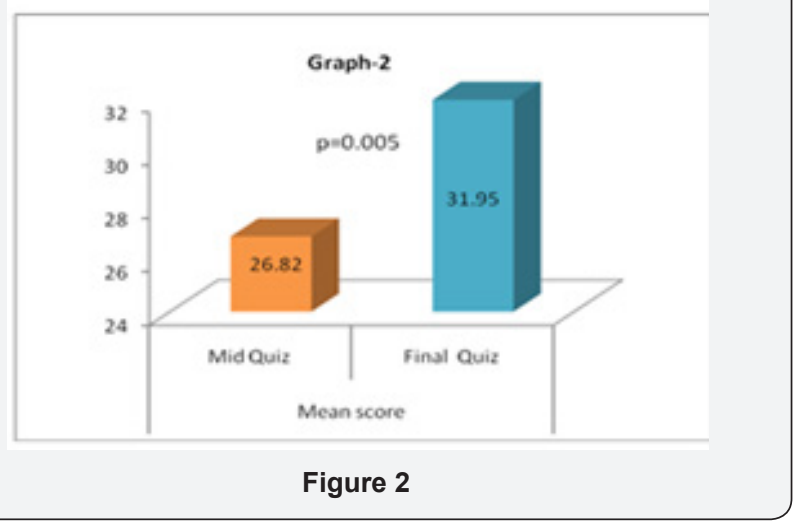

The mean score of male and female in midterm was reported as $26.45 \pm 5.59$ and $27.10 \pm 6.77$ which shows insignificant differences between mean scores of both gender ( $\mathrm{p}=0.799)$. In final term, the mean score was reported as $33.72 \pm 8.12$ in males and $30.46 \pm 12.14$ in females. Another finding of the study narrated that female had higher score while assessing training program while male had higher varied score while assessing organizational effectiveness. Zulfiqar Ali [6] in pre-test, the mean score was reported as $10.90 \pm 2.02$ in males and $10.50 \pm 1.99$ in females. In post-test, the mean score was reported as $12.25 \pm 2.43$ in males and $12 \pm 1.41$ in females. We found insignificant differences in mean scores of final terms $(p=0.456)$, pre-test $(p=0.617)$ and posttest $(\mathrm{p}=0.768$ ) with respect to gender. The detailed frequency distribution according to gender is presented in Table 1. According to different institute participants, the differences in mean scores obtained from different institutes participants were also found significant in midterm $(\mathrm{p}=0.025)$ and final term $(\mathrm{p}=0.031)$. There is no significant difference was found in mean scores of pretests $(\mathrm{p}=0.888)$ and posttest $(\mathrm{p}=0.371)$. The detailed frequency distribution of different institute participants is presented in Table 2.

Table 1: Comparison of obtained marks between different genders.

\begin{tabular}{|c|c|c|c|c|}
\hline $\begin{array}{c}\text { Marks } \\
\text { Obtained }\end{array}$ & $\begin{array}{c}\text { Overall } \\
\text { Mean } \pm \text { SD }\end{array}$ & $\begin{array}{c}\text { Male Mean } \\
\mathbf{\pm S D}\end{array}$ & $\begin{array}{c}\text { Female } \\
\text { Mean } \pm \text { SD }\end{array}$ & P-value \\
\hline Mid Quiz & $26.82 \pm 6.16$ & $26.45 \pm 5.59$ & $27.10 \pm 6.77$ & $0.799^{* *}$ \\
\hline Sec A & $8.36 \pm 1.49$ & $8.63 \pm 1.50$ & $8.14 \pm 1.51$ & $0.425^{* *}$ \\
\hline Sec B & $5.84 \pm 2.19$ & $5.45 \pm 2.04$ & $6.14 \pm 2.33$ & $0.448^{* *}$ \\
\hline Sec C & $12.44 \pm 4.36$ & $11.95 \pm 3.93$ & $12.82 \pm 4.78$ & $0.632^{* *}$ \\
\hline Final Quiz & $31.95 \pm 10.41$ & $33.72 \pm 8.12$ & $30.46 \pm 12.14$ & $0.456^{* *}$ \\
\hline Pre-Test & $10.68 \pm 1.97$ & $10.90 \pm 2.02$ & $10.50 \pm 1.99$ & $0.617^{* *}$ \\
\hline Post- test & $12.10 \pm 1.81$ & $12.25 \pm 2.43$ & $12 \pm 1.41$ & $0.768^{* *}$ \\
\hline
\end{tabular}

Table 2: Comparison of obtained marks among different hospitals.

\begin{tabular}{|c|c|c|c|c|}
\hline $\begin{array}{c}\text { Marks } \\
\text { Obtained }\end{array}$ & $\begin{array}{c}\text { LNH Mean } \\
\pm \text { SD }\end{array}$ & $\begin{array}{c}\text { HUH Mean } \\
\mathbf{\pm} \text { SD }\end{array}$ & $\begin{array}{c}\text { MMH Mean } \\
\mathbf{\pm S D}\end{array}$ & P-value \\
\hline Mid Quiz & $25.18 \pm 4.85$ & $34 \pm 6.21$ & $28 \pm 10.60$ & $0.025^{*}$ \\
\hline Sec A & $8.26 \pm 1.62$ & $8.75 \pm 0.50$ & $8.50 \pm 2.12$ & $0.843^{*}$ \\
\hline Sec B & $5.47 \pm 1.67$ & $7.87 \pm 2.83$ & $5.25 \pm 4.59$ & $0.126^{* *}$ \\
\hline Sec C & $11.23 \pm 3.63$ & $17.25 \pm 2.98$ & $14.25 \pm 8.13$ & $0.028^{*}$ \\
\hline Final Quiz & $29.38 \pm 9.96$ & $44 \pm 5.83$ & $31 \pm 1.41$ & $0.031^{*}$ \\
\hline Pre-Test & $10.73 \pm 1.91$ & $10.25 \pm 2.98$ & $11.00 \pm 00$ & $0.888^{* *}$ \\
\hline Post- test & $12.06 \pm 1.88$ & $13.00 \pm 1.0$ & $10.00 \pm 00$ & $0.371^{* *}$ \\
\hline
\end{tabular}

ANOVA test is applied

*Significant at $<0.05$

** Insignificant at $>0.05$

Study not only showed substantial and positive impact of training on nurses. With $\mathrm{p}=0.005$ and $\mathrm{p}=0.002$ that validates scope of continuous nursing education. Training motivated Nurses endure high quality care to neonates and to have sound proficiency at NICU. Analyzing the Results of Mid Quiz Sectional Review was taken below mean score in Mid Quiz. Mean Score seen high in Section C based on small essay questions. So final was prepared on analysis made on participants understanding to comprehend thing well in short essay questions since it was first time such training was done so at all levels comforts were taken in account for better understanding of NICU concepts.

\section{Discussion}

Pediatric and Neonatology (2015) [7] by Rocio. M. Pena had coherent discussion under critique "impact of a developmental care training course on knowledge .... In neonatal Unit" that nurses working in NICU received no training in developmental care. Given continuous advances and changes in Medical Era has caused health professionals to enroll in Continuous education to acquire and maintain skills. A lucid discussion was made in terms 
of training NICU nurses that after long time field of Neonatology realized to take and initiate training among such group of nurses who in actual working for population who cannot speak for themselves. Training based on six major categories that completed circle of neonatal care; Peads Surgery, Peads Medicine, Peads Infectious Disease, Neurological, Bio-Ethics and Basic neonatal Care. A systematic approach to care was given by group of trainers that helped nurses to understand disease process and to monitor and be acquainted with danger signs in neonates. It focused on ethical decision making, care of dying neonates, bereavement, and cultural communication Murakami [8].

Concept of early warning signs was especially been put in course as real and most underlying threatening emergencies are detected through this. This section as covered mainly through case studies that promoted critical thinking of Nurses. It gave acknowledgement to them to figure out and execute type of intercession demanded by condition or an event encountered by neonates. The ideal time frame for frequency of resuscitation skills training has yet to be determined. Results obtained from this performance improvement project using hands-on practice sessions [9]. Moreover, team approach is expected in all decisions made for the patients in and during CPR, Carrying out invasive procedure like intubation and administration of surfactant therapy, Blood Exchange Transfusion and its monitoring during Cycles of In-and Out, Peritoneal Dialysis etc. Training gave an opportunity to retain knowledge of nurses and to be more efficient in using and implementing care plans that resulted in positive outcomes.

Peads Surgery had the most flexible approach in making participants to learn about special surgical series. Case presentation was made on diseases like NEC; Hirsch sprung Disease, bowel obstructions or atresia, TEF, Congenital Diaphragmatic hernia. There were five groups each group headed by a surgery resident as facilitator. Peads Surgeon foster discussion on cases those significantly were useful. Apart from this at end of each case presented discharge teaching and care instructions for parents in most easy and simple language was demonstrated by peads surgery residents. There is a strong gap between theory and practice in nursing field and the nurses pay more attention to scientific and skill aspects than science and art of nursing. During the last two decades, almost all countries have been confronted with increasing demands for health services Borzadady Farahani [10]. Data collection was made by taking Pre and Post Test of Infection Control Module, Mid and Final Quiz based on Assessing Knowledge about Disease Process and Nursing Responsibilities. Reflective writings were found to be the most significant contrivance to evaluate over all courses. It gives us prospect to learn about participants need and expectations as it received after a one complete session cycle. Few Examples of reflective writing were as follows:

"We felt fortunate to be part of training and team together thought to train us, this was the moment awaited to retain my knowledge". (Mid Age Nurses of NICU). "Handling Neonates had always been risky and difficult mainly for activities like positioning them with tubes and invasive lines, bathing and weighing them daily, measuring length, FOC \& Plotting it to growth graph, abdominal girth measuring, feeding babies through NG/OG, Cup and Spoon, Routine Care: Eye Care, Skin Care, mouth Care, Perineal Care, invasive line care. We were doing because we were taught but this training gave rational to all are actions and now we are aware to bring change in practices to promote more of the neonate safety. (Nurse Midwife - NICU) "It was very hard to engulf these big concepts of tiny world (neonates). We never thought Neonatology basics will be a giant step to learn as academics do not have these in their curricula". (Newly Hired Novice Nurse).

Revista Latino-Americana de Erfermagem [11] affirmed that another factor associated with the appropriateness of continuous education is the role of management. The reality of academic training for nursing professionals has changed radically in recent decades in terms of maintaining the rhythm of current clinical practice. The study has created a platform for Senior Management, faculties, nursing leaders to plan such comprehensive training programs and to carry on learning wheel to empower and retain nurses. This act ultimately will improve patient safety and satisfaction level. Clinical decision participation is promoted to improve recovery level. Limitation of study was, only knowledge was assessed in summative while clinical evaluation was not assessed collectively. In addition, it was small scale study. Despite for it been small scale to its limitation it showed participants eagerness, interest and thirst to learn and grow in this specialty. It postulated to influence nurses to bring change in behavior and attitude while caring for neonate with dissimilar diseases processes. Research on developmental care (2005) by Isabelle, Lucie and Marie Confirm that small scale is ambitious and help to convince nurses, planners, decision makers for the potentials of training offers for health and development of premature infants.

\section{Conclusion}

Frequent sittings were done in different phases of training with trainers: Pre-Phase, Mid-Phase and Post-Phase helped us to modified things. Debriefing was done for all process of trainings: Skills Sign Off, Quizzes and Presentations. We hope that upon completion of training there would be a significant change in nursing practices an. It was efforts of team which resulted in constructive outcomes. Adequate training and orientation when starting their career, and continuing education throughout their career, were of significant importance to student nurses. Continuing education was seen as a career-long component of a nursing career. Student nurses believed that their formal education only provided them with a starting point, with an understanding that additional training, learning and education would take place throughout their career Price S [12]. Study showed the impact of training on all participation and validated the significance of continuous nursing education and contributed to make nurses valuable and safe by enduring high quality care to neonates and helped nurses to have sound proficiency at NICU. A study also indicated that trained healthcare working force is crucial in tertiary care hospitals of Pakistan [6]. 


\section{Recommendations}

We comprehend that the theory and practice all are correlated, and having Knowledge is not ample to be proficient till hands on is been effectual to care for neonates. Team mutually agreed to include clinical and Skills summative assessment and explore team coordination and dynamics in caring for new borns. Moreover, large Scale studies to be conducted among different group of nurses at different intervals that can go with other sub-specialties.

\section{References}

1. Heidari H, Hasanpour M, Fooladi M (2017) Stress management among parents of neonates hospitalized in NICU: a qualitative study. J Caring Sci 6(1): 29-38.

2. Milette IH, Richard L, Martel MJ (2005) Evaluation of a developmental care training programme for neonatal nurses. J Child Health Care 9(2): 94-109.

3. Price S (2015) Bridging the Generational Divide: Nurses United in Providing Quality Patient Care, CFNU. Ottawa, Canada 1(1): 1-84.

4. Hsu LL, Chang WH, Hsieh SI (2015) The effects of scenario-based simulation course training on nurses' communication competence and self-efficacy: a randomized controlled trial. J Profession Nursing 31(1): 37-49.

5. Mira VL, Follador NN, Ferrari CR, Oliveira LF, Silva JA, et al. (2012) Evaluation of effectiveness of training of nursing professionals: a correlational study. Online Brazilian J Nurs 11(3): 595-606.
6. Zulfiqar Ali, Mehwish Hussain (2014) The Impact of Training Program on Organizational Effectiveness: A Case Study of Healthcare Organization in Karachi-Pakistan. Bio safety 3(2): 119-25.

7. (2015) Impact of a Developmental Care Training Course on the Knowledge and Satisfaction of Health Care Professionals in Neonatal Units: A Multicenter Study Author links open overlay panel Rocío Mosqueda-Peñaa David Lora-Pablosb Abraham Pavón-Muñozc Noelia Ureta-VelascoaMaría TeresaMoral-Pumaregaa Carmen RosaPallásAlonsoa.

8. Murakami M, Yokoo K, Ozawa M, Fujimoto S, Funaba Y, et al. (2015) Development of a Neonatal End-of-Life Care Education Program for NICU Nurses in Japan. J Obstet Gynecol Neonat Nursing 44(4): 481-91.

9. Ciurzynski SM, G Ottfried JA, Pietraszewski J, Zalewski M (2017) Impact of Training Frequency on Nurses' Pediatric Resuscitation Skills. J Nurses Profession Develop 33(5): 1-7.

10. Borzabady Farahani Z, Rastian M, Rassouli M, Sarbakhsh P (2016) The Impact of Training on Nursing Process Implementation Skills of Surgical Ward Nurses. Intern J Med Resear Health Sci. 5(7): 268-72.

11. Ortega MD, Cecagno D, Llor AM, Siqueira HC, Montesinos MJ, et al. (2015) Academic training of nursing professionals and its relevance to the workplace. Latin American Journal of Nursing 23(3): 404-410.

12. Price S, Reichert C (2017) The importance of continuing professional development to career satisfaction and patient care: Meeting the needs of novice to mid-to late-career nurses throughout their career span. Admin Sci 7(2): 17-30.

\section{Your next submission with Juniper Publishers} will reach you the below assets

- Quality Editorial service

- Swift Peer Review

- Reprints availability

- E-prints Service

- Manuscript Podcast for convenient understanding

- Global attainment for your research

- Manuscript accessibility in different formats

( Pdf, E-pub, Full Text, Audio)

- Unceasing customer service

Track the below URL for one-step submission https://juniperpublishers.com/online-submission.php 